\title{
Sistema de indicadores para avaliação da sustentabilidade ambiental de comunidades ribeirinhas
}

\author{
Larissa Boing $^{1 \star}$ (D), Salvador Dal Pozzo Trevizan ${ }^{1}$ (D), Walter Fagundes Morales² (iD \\ 1 Programa de Pós Graduação em Desenvolvimento e Meio Ambiente, Universidade Estadual de Santa Cruz, Campus \\ Soane Nazaré de Andrade - Pavilhão Jorge Amado, Rodovia Jorge Amado, Km 16, Bairro Salobrinho, Ilhéus, Bahia - \\ 45662-900. \\ 2 Programa de Pós-Graduação em História: Atlântico e Diáspora Africana, Universidade Estadual de Santa Cruz, \\ Campus Soane Nazaré de Andrade, Rod. Jorge Amado, Km 16 - Salobrinho, Ilhéus - BA, 45662-900. \\ *Autora para correspondência: boing.larissa@gmail.com
}

Recebido em 30 de novembro de 2020.

Aceito em 05 de março de 2021.

Publicado em 15 de junho de 2021.

Resumo - A busca pelo equilíbrio entre o desenvolvimento socioeconômico e a conservação do ambiente natural é uma questão imperativa na atualidade para garantir qualidade de vida às sociedades humanas e condições de vida na Terra. Entretanto, por ser a sustentabilidade um conceito abstrato, um dos desafios para a efetividade desse ideal é unir a teoria à prática. Sistemas de indicadores têm sido elaborados com o objetivo de auxiliar o ser humano nessa tarefa. O presente artigo tem como objetivo apresentar um sistema de indicadores voltado à avaliação da sustentabilidade ambiental de comunidades ribeirinhas que tenham a pesca artesanal, a agricultura e o turismo como principais atividades econômicas. A aplicação do instrumento foi realizada junto à comunidade do entorno da Lagoa Encantada, situada no município de Ilhéus, sul do estado da Bahia, Brasil, cujos resultados apontam uma baixa sustentabilidade ambiental. Destaca-se a metodologia como um diferencial deste estudo, ao envolver a comunidade na discussão dos indicadores e instrumento de coleta de dados, selecionados a partir de revisão de literatura, tornando o sistema de indicadores em questão sensível às variáveis do contexto local, sem perder sua objetividade e universalidade.

Palavras-chave: Indicadores de sustentabilidade. Desenvolvimento sustentável. Comunidades tradicionais.

\section{System of indicators for assessing the environmental sustainability of ribeirin communities}

Abstract - The search for balance between socioeconomic development and the conservation of the natural environment is an imperative issue to ensure quality of life to human societies and living conditions on Earth. Systems of sustainability indicators have been developed to assist in decision making towards sustainable development. This article aims to introduce a system of indicators aimed at assessing the environmental sustainability of riverain communities with artisanal fishing, agriculture and tourism as their main economic activities. The instrument was applied to the community of the Surroundings of Lagoa Encantada, located in the municipality of Ilhéus, south of the State of Bahia, Brazil, with results pointing to low environmental sustainability. Methodology is the main issue of this study, by involving the community in the discussion of indicators and data collection 
instrument, selected from the literature review, making the system of indicators in question sensitive to the variables of the local context, without losing its objectivity and universality.

Keywords: Sustainability indicators. Sustainable development. Traditional communities.

\section{Sistema de indicadores para evaluar la sostenibilidad ambiental de las comunidades ribereñas}

Resumen - La búsqueda del equilibrio entre el desarrollo socioeconómico y la conservación del medio ambiente es hoy un tema imperativo para garantizar la calidad de vida de las sociedades humanas y las condiciones de vida en la Tierra. Sin embargo, dado que la sostenibilidad es un concepto abstracto, uno de los desafíos para la efectividad de este ideal es combinar la teoría con la práctica. Se han desarrollado sistemas de indicadores con el objetivo de ayudar a los seres humanos en esta tarea. Este artículo tiene como objetivo presentar un sistema de indicadores orientados a evaluar la sostenibilidad ambiental de comunidades ribereñas que tienen como principales actividades económicas la pesca artesanal, la agricultura y el turismo. El instrumento se aplicó a la comunidad del Entorno de Lagoa Encantada, ubicada en el municipio de Ilhéus, al sur del estado de Bahía, Brasil, cuyos resultados apuntan a una baja sostenibilidad ambiental. Se destaca la metodología como diferencial de este estudio, al involucrar a la comunidad en la discusión de indicadores e instrumento de recolección de datos, seleccionados de la revisión de la literatura, haciendo que el sistema de indicadores en cuestión sea sensible a las variables del contexto local, sin perder su objetividad y universalidad.

Palabras clave: Indicadores de sostenibilidad. Desarrollo sustentable. Comunidades tradicionales.

\section{Introdução}

Desde a década de 1980, sistemas de indicadores têm sido elaborados com o objetivo de auxiliar na prática de um desenvolvimento que seja sustentável. Entretanto, somente a partir da Conferência das Nações Unidas para o Meio Ambiente e Desenvolvimento, em 1992, que a elaboração e a utilização dos mesmos foram impulsionadas, ganhando espaço no âmbito governamental e influenciando políticas públicas (Rayén Quiroga 2001). Tais ferramentas têm o intuito de descrever a interação entre os grupos sociais e os ambientes onde residem, identificando seus pontos de conflitos e suas potencialidades e, ao mesmo tempo, orientando a tomada de decisão rumo a maior harmonia entre os mesmos.

A identificação da sustentabilidade em um âmbito de comunidades, por sua vez, tem como desafio um sistema que seja sensível às particularidades locais, cujos padrões de produção, consumo e de bem-estar sejam definidos a partir de sua cultura, de seu desenvolvimento histórico, bem como das características de seu ambiente natural, especialmente quando seu modo de vida está diretamente ligado à dinâmica da natureza, como nas comunidades ribeirinhas. Ribeirinhos são “[...] trabalhadores e trabalhadoras que residem nas proximidades dos rios e, que há muito caracterizam-se por ter como principal atividade de subsistência a pesca" (Neves 2004, p. 01). O rio e a mata são elementos centrais do cotidiano dessas comunidades, e o atendimento de suas necessidades e atividades produtivas dependem, inteiramente, do que a natureza local lhes oferece e dos conhecimentos adquiridos sobre ela (Grzebieluka 2012; Ribeiro 2012). Entretanto, procedimentos metodológicos que permitam 
dimensionar o nível de sustentabilidade ambiental em que se encontra uma comunidade de ribeirinhos, fortemente dependente de recursos naturais, como água, vegetação e solo, entre outros são escassos. Considera-se que o uso de indicadores que leve em consideração os elementos acima indicados, tais como, produção, consumo, bem-estar e componentes do ambiente natural pode ser um bom caminho para se delinear procedimentos metodológicos adequados para tanto. A avaliação da sustentabilidade em âmbito de comunidades possibilita identificar de forma mais adequada os problemas e os desafios locais, bem como propor medidas para solucioná-los.

O presente artigo tem como objetivo, assim, apresentar um sistema de indicadores voltado à avaliação da sustentabilidade ambiental de comunidades localizadas em ambiente ribeirinho que possuem a pesca artesanal, a agricultura e o turismo como principais atividades econômicas. O sistema foi desenvolvido e aplicado na comunidade ribeirinha localizada no entorno imediato da Lagoa Encantada, situada no distrito de Castelo, município de Ilhéus, região sul do estado da Bahia, Brasil, composta pelos moradores de Vila de Areias e das propriedades rurais que margeiam a lagoa, cujas atividades de geração de renda e subsistência são as supracitadas. Trata-se, portanto, de uma pesquisa que visa desenvolver e aplicar numa realidade concreta procedimentos metodológicos que permitam avaliar o nível de sustentabilidade ambiental de uma comunidade, replicável a outras comunidades com características semelhantes.

\section{Sustentabilidade ambiental - conceito, dimensões e indicadores}

Desde que se constatou que os recursos naturais da terra eram finitos e estavam a caminho de seu esgotamento, passou-se a problematizar a maneira como o desenvolvimento econômico dos diferentes países deveria ser conduzido. O conceito de desenvolvimento sustentável surge nesse contexto. Divulgado com a publicação do Relatório Brundtland, em 1987, e popularizado com a Eco 92, é designado como o desenvolvimento que satisfaz as necessidades do presente sem comprometer a capacidade das futuras gerações em satisfazer as suas próprias necessidades (CMMAD 1991). O termo tem sido criticado por buscar a sustentabilidade do desenvolvimento em uma sociedade capitalista baseada em um modelo de produção e consumo que já se mostraram insustentáveis (Gadotti 2000). Apesar do aparente consenso que existe a respeito do termo, por ser um conceito bastante amplo, é apropriado de maneira diferente por cada grupo social que o utiliza. Diegues (2003, p. 5) expõe de maneira clara essa questão:

\footnotetext{
Para certos setores do movimento ambientalista significa uma proteção do 'verde' independente da realidade social envolvida. Para os empresários trata-se, no fundo, do desenvolvimento que possa garantir a 'sustentabilidade' da taxa de lucro, baseada sobretudo na criação e venda dos equipamentos contra a poluição. Para certos governos, o termo muitas vezes constitui o preâmbulo de documentos oficiais para solicitação de empréstimos internacionais a organismos financeiros que foram obrigados a introduzir em seus critérios de aprovação de projetos as variáveis ambientais.
}

No mesmo trabalho, Diegues incita à reflexão da sustentabilidade ligada ao bem-estar e à qualidade de vida das comunidades e sociedades humanas, a partir da reafirmação de seus elementos históricos e culturais. O objetivo, assim, para esse autor, deixa de ser o desenvolvimento da economia 
e passa a ser a "construção" de comunidades e sociedades sustentáveis, com padrões de produção, consumo e bem-estar definidos a partir das especificidades locais.

A despeito das críticas que se faz ao conceito de sustentabilidade, Loureiro et al. (2003) colocam que o debate por ele motivado tem sido bastante útil como uma 'ideia-força' importante para a busca de um novo modelo civilizatório.

Nesse estudo, o adjetivo "ambiental” é associado à sustentabilidade, visando enfatizar a relação entre as ações humanas e o espaço onde elas ocorrem. Nessa perspectiva, a sustentabilidade ambiental pode ser compreendida como a interação saudável do ser humano com seu habitat, considerando uma alta qualidade de vida para as comunidades humanas ali existentes.

A avaliação da sustentabilidade de uma determinada comunidade envolve, frequentemente, o levantamento e a aplicação de indicadores, os quais podem ser entendidos como uma medida que resume informações importantes sobre determinado fenômeno ou realidade (Malheiros et al. 2012). Van Bellen (2006) enfatiza que os indicadores costumam simplificar informações sobre fenômenos complexos e facilitar a compreensão dos mesmos. O autor ressalta, entretanto, a importância de serem de fácil entendimento e transparentes, para que os usuários compreendam seu significado a partir de seus valores e sua cultura, e haja efetiva comunicação das informações coletadas.

A seleção de indicadores de sustentabilidade pode ser feita seguindo abordagens conforme o objetivo do estudo. No modelo top-down (de cima para baixo) especialistas definem o sistema e o grupo de indicadores sem interferência dos usuários, tendo como vantagem o fato deste ser mais homogêneo, de fácil comparação e mais válido do ponto de vista dos referenciais teóricos, uma vez que considera indicadores globalmente definidos como importantes (Van Bellen 2006). Já, de acordo com o autor, na abordagem bottom-up (de baixo para cima) os temas e os indicadores são selecionados com a participação de representantes locais, sendo que há maior apropriação do sistema pela comunidade, bem como suas prioridades são incluídas no processo, porém, com a possibilidade de se omitir aspectos essenciais à sustentabilidade. Reed et al. (2006) enfatizam que há uma sensibilização no mundo acadêmico quanto à necessidade de desenvolver metodologias que mesclem ambas as abordagens. Elas permitiriam superar fragilidades e inserir vantagens de ambas, processo esse que se buscou adotar no presente estudo.

A elaboração e seleção de indicadores para a avaliação da sustentabilidade ambiental demanda um olhar sistêmico para um conjunto de fatores, que podem ser agrupados em dimensões ou subsistemas (Gallopín 2003). Atualmente, há um consenso de que as dimensões social, econômica e dos recursos naturais contemplem os principais ingredientes do que se entende por sustentabilidade ambiental (Mauerhofer 2007). Essas três dimensões serão trabalhadas nesta pesquisa para dimensionar a sustentabilidade ambiental de uma comunidade com características específicas: comunidade ribeirinha. Para uma região litorânea da Mata Atlântica, cortada por frequentes mananciais aquáticos, rica em biodiversidade, recursos esses dos quais dependem inúmeras comunidades remanescentes de quilombolas, indígenas e outras aglomerações humanas que sobrevivem da pesca artesanal, do extrativismo e da agricultura familiar, o desenvolvimento de um instrumental específico que possibilite avaliar o nível de sustentabilidade ambiental em que se encontram representa uma possibilidade a mais para a implementação de programas de desenvolvimento local ambientalmente sustentável. 
$\mathrm{Na}$ sequência, apresenta-se a discussão sobre a operacionalização das três dimensões da sustentabilidade ambiental de uma comunidade ribeirinha.

A dimensão social da sustentabilidade faz referência à preocupação com o bem-estar humano e os processos que garantem o alcance dessa condição (Mckenzie 2004; Van Bellen 2006). A partir dessa perspectiva, alguns dos indicadores importantes de serem avaliados nessa dimensão são tanto os de caráter subjetivo, como os relacionados ao capital social e à relação afetiva entre as pessoas e o local onde habitam, bem como os indicadores objetivos, concernentes aos requisitos universais para a obtenção de desenvolvimento de longa duração, como o acesso à educação, segurança pública e serviços de saúde (Sachs 2004).

O capital social pode ser entendido como os traços da vida social que facilitam a ação e a cooperação na busca de objetivos comuns (Putnam 2006). Grootaert et al. (2003), após uma ampla revisão de literatura sobre o conceito, propõem que sua identificação seja feita a partir de seis componentes, a saber: i) grupos e redes, ii) confiança e solidariedade, iii) ação coletiva e cooperação, iv) informação e comunicação, v) coesão e inclusão social, e vi) empoderamento e ação política.

O componente "grupos e redes" é o mais comumente associado ao conceito e se refere à natureza e à extensão da participação do membro de um domicílio em organizações sociais e redes informais, assim como as contribuições dadas e recebidas nestas relações; a dimensão "confiança e solidariedade" diz respeito à confiança que inspira vizinhos, prestadores de serviço e pessoas desconhecidas e sua percepção sobre o tema; já "ação coletiva e cooperação" corresponde à participação e ao envolvimento das pessoas em projetos conjuntos; o componente "informação e comunicação" considera que o empoderamento comunitário depende da informação e do acesso a canais de comunicação e explora a infraestrutura de comunicação existente no local; a categoria "coesão e inclusão social" insere as diferenças e os conflitos existentes nas comunidades na pauta de discussão do capital social, e coloca que a natureza e o tamanho dessas diferenças, bem como a forma de interação entre seus membros, são maneiras de se analisar este componente; e por fim, a dimensão "poder e ação política" diz respeito à percepção das pessoas quanto à capacidade de exercerem influência sobre os eventos locais, tanto quanto sobre as respostas políticas mais amplas (Grootaert et al. 2003). Assim, compreender as condições de bem-estar humano em uma comunidade supõe avaliar a densidade de seu capital social.

A relação afetiva entre as pessoas e o local onde habitam, a topofilia, é outro fator que pode ajudar a definir a sustentabilidade da dimensão social. O termo foi difundido por Tuan (1980) em sua obra homônoma e é utilizado como sinônimo da atração do ser humano pelos aspectos físicos, especialmente paisagísticos, de um determinado ambiente. A topofilia é marcada por aspectos culturais como a afetividade, a memória e as vivências, atribuindo ao lugar um importante papel na composição da identidade local (Yázigi 2001).

Em se tratando da sustentabilidade da dimensão econômica, faz-se importante conhecer algumas teorias econômicas surgidas a partir dos movimentos ambientais e das críticas às teorias desenvolvimentistas, as quais ajudaram a aprofundar o debate sobre os componentes dessa dimensão, como a economia ambiental neoclássica e a economia ecológica.

A Economia Ambiental Neoclássica se preocupa, sobretudo, em resolver o problema das externalidades, que são os custos ambientais, ou benefícios, quando são externalidades positivas, produzidos pelo funcionamento do mercado (Walter 2002). A ideia central da teoria é que toda externalidade precisa se converter em um valor que precisa ser inserido no custo de um produto ou 
serviço para que o mesmo reflita seu verdadeiro valor. Caso contrário, apenas os custos privados são internalizados, sendo que os demais acabam sendo assumidos pela sociedade (Montibeller 2004). Essa teoria gerou ideias bastante úteis como o princípio do poluidor pagador, um dos princípios básicos do direito ambiental atual, a questão dos direitos de propriedade dos bens comuns e acelerou o trabalho de avaliação dos custos e benefícios ambientais que não são pagos pelos mecanismos de mercado (Walter 2002; Montibeller 2004).

Já a Economia Ecológica analisa a estrutura do processo econômico da relação ser humano e a natureza a partir dos fluxos de energia e materiais. Ela se utiliza de conceitos da ecologia como a Teoria Geral dos Sistemas, o conceito de capacidade de carga e as leis da termodinâmica para explicar a inter-relação do ser humano com o meio em que se insere (Montibeller 2004). Esta teoria critica a valoração monetária dos bens ambientais em virtude da incomensurabilidade de valores, ou seja, da impossibilidade de valorar aquele bem devido a intergeracionalidade, uma vez que o valor atribuído a certo bem pela geração atual não consegue revelar quanto ele seria avaliado pelas gerações futuras, e por essa valoração não considerar a degradação ambiental, camuflando, com isso, um sistema de troca ecologicamente desigual, no qual um produtor, empresa, região ou país poderia estar vendendo um recurso natural a um baixo custo, por não computar nesse valor a degradação física e social deixada na área de produção (Montibeller 2004).

Entretanto, ao se voltar a atenção a uma perspectiva de comunidades, em especial àquelas que dependem diretamente dos recursos naturais para a produção de bens primários, como as comunidades ribeirinhas, a Economia Ambiental mostra-se muito geral e abstrata, bem como a Economia Ecológica que, apesar de conseguir atender algumas demandas locais, dá pouca ênfase ao que é coletivo (Walter 2002). Assim, o autor propõe que a sustentabilidade econômica em comunidades seja conceituada como o uso dos recursos para a realização de uma alta qualidade de vida individual e social, ou seja, que o potencial do ser humano seja desenvolvido dentro de um contexto de apoio da comunidade e de aversão ao dano de outras, conceito esse adotado no presente trabalho como base para a seleção dos indicadores de sustentabilidade da dimensão econômica.

Uma alta qualidade de vida, depende, dentre outros fatores, das condições de emprego e renda identificadas. Assim, faz-se necessário avaliar a oferta de trabalhos, bem como a renda mínima necessária para a reprodução da família, no tempo, na localidade que está sendo estudada (Rodrigues et al. 2003), o que inclui conhecer o panorama do autoconsumo local, uma vez que ele se configura como um dos elementos estratégicos para o desenvolvimento sustentável, pois se torna uma renda indireta, diminuindo as despesas da família com a manutenção alimentar, bem como pode significar o consumo de alimentos de maior qualidade (Pelinski et al. 2006).

A sustentabilidade ecológica ou dos recursos naturais, por sua vez, corresponde ao estado de conservação da natureza externa ao ser humano (Foladori 2002). Conforme o autor, o critério para medir essa conservação remete ao conceito de integridade da natureza: quanto mais perto da natureza "original", maior a sustentabilidade ecológica e por sua vez, quanto mais humanamente modificada estiver a natureza, menor seria a sustentabilidade desta.

Para a seleção dos recursos naturais a serem avaliados em realidades de comunidades ribeirinhas, recorre-se ao Materialismo Histórico, para o qual, o ser humano produz sua vida material a partir dos seus meios de existência, e os meios de existência dependem, em primeiro 
lugar da natureza (Marx 1977). Assim, a sustentabilidade dessa dimensão pode ser medida a partir do nível de conservação dos recursos naturais (bióticos e abióticos) utilizados para a produção da vida material que acontece, sobretudo, por meio do trabalho. As atividades que são fontes de renda e subsistência de uma determinada comunidade passam a ser base para a observação da sustentabilidade da dimensão dos recursos naturais.

\section{Material e métodos}

O processo metodológico envolveu a definição das dimensões, temas e seleção prévia dos indicadores que iriam integrar o sistema, selecionados com base na revisão de literatura, incluindo estudos de modelos de sistemas de indicadores de sustentabilidade de comunidades ribeirinhas e de base ecológica (Barreto et al. 2005; Andrade 2007; Rabelo e Lima 2007), bem como uma etapa de reconhecimento da área escolhida para aplicação da pesquisa, com visitas de campo e um período de observação participante. ${ }^{1}$

Realizou-se, então, a discussão do formulário de coleta de dados com a comunidade, de modo que o instrumento fosse sensível às variáveis do contexto local. O cuidado de não se levantar expectativas de futuras intervenções a partir da pesquisa fez com que se optasse por mobilizar uma quantidade pequena de pessoas nessa etapa. A discussão foi feita com duas lideranças locais, as quais tiveram dúvidas e ponderações parecidas. Alguns indicadores e questões do formulário foram retirados e/ ou modificadas a partir dessas reflexões. Na sequência, aplicou-se o pré-teste do instrumento, que indicou a necessidade de adequação de algumas palavras, como o nome dos atrativos turísticos locais, bem como a ordem de algumas perguntas, visando maior fluidez na aplicação do mesmo. Assim, buscou-se mesclar as abordagens top-down e bottom up no processo de construção do presente sistema de indicadores (Reed et al. 2006).

\section{População e amostra}

A pesquisa foi realizada junto à comunidade ribeirinha localizada no entorno imediato da Lagoa Encantada, situada no distrito de Castelo, município de Ilhéus, região sul do estado da Bahia, Brasil, composta pelos moradores de Vila de Areias e das propriedades rurais que margeiam a lagoa (Figura 1). A unidade de observação da pesquisa foi a família, entendendo-se família como aqueles que moram em uma mesma residência, independente de possuírem laços de parentesco. A amostra tomou como base o total de 158 casas habitadas na comunidade, em agosto de 2014, pressupondo que cada casa habitada abrigue uma família. Considerando um erro amostral de 5\% e de um nível de confiança de 95\%, a amostra foi dimensionada em 115 casas.

1 A pesquisadora permaneceu na casa de uma das famílias da comunidade estudada por um período de quatro dias durante a observação participante, realizada em novembro de 2013. Entretanto, das visitas de reconhecimento até a aplicação dos formulários de coleta de dados, totalizaram-se mais 30 dias de permanência na comunidade, entre maio e agosto de 2014. 
Figura 1. Localização da área de estudo: Vila de Areias e propriedades rurais do entorno da Lagoa Encantada, Ilhéus, Bahia.
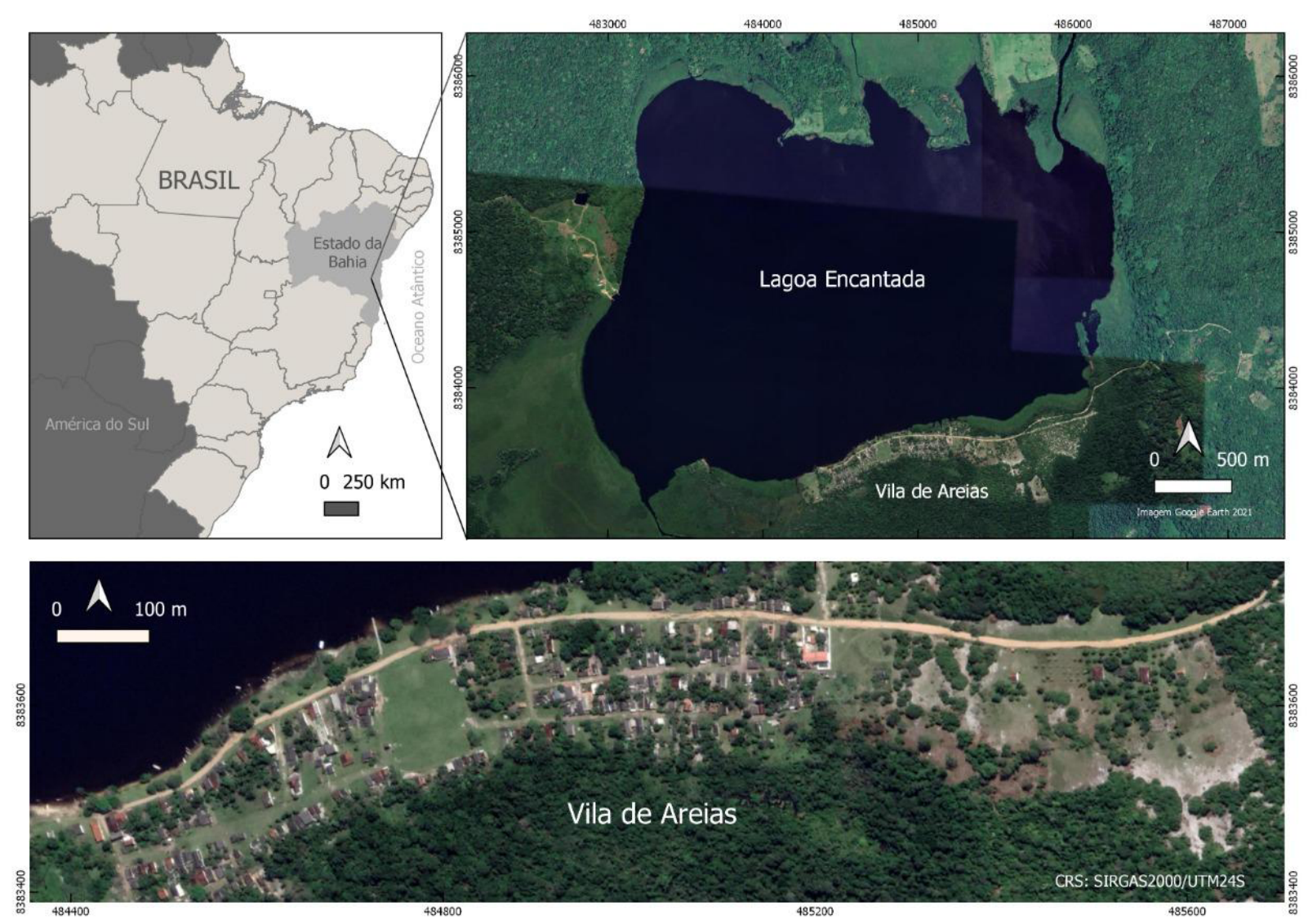

Fonte: Elaborado pelos autores a partir da base de dados do Google Earth (2021).

A seleção das moradias para a pesquisa ocorreu de forma aleatória sistemática e o formulário foi aplicado junto a um morador adulto, com mais de 18 anos, em condições de informar a respeito dos residentes do imóvel, mediante a leitura e assinatura do Termo de Consentimento Livre e Esclarecido (TCLE).

\section{Indicadores e escala de sustentabilidade}

Excetuando-se os indicadores 1a, 1b, 2a, 4a, 8a, 19a e 19b, a escala de qualificação dos demais é adaptada de Likert (Gil 2008) e indica o nível de concordância em relação à afirmação, variando de discordância total (zero) à concordância total (quatro), conforme Quadros 1, 2 e 3.

Na sustentabilidade da dimensão social, avaliou-se o acesso à saúde e à educação, a mobilidade e acessibilidade, a segurança pública, a manutenção da cultura local, o capital social e a topofilia (Quadro 1). Como um dos aspectos considerados essenciais para a saúde humana é o acesso à água potável e, uma vez que a comunidade pesquisada não é atendida pelo sistema público de abastecimento de água, a escala de sustentabilidade desse indicador levou em conta as formas de abastecimento de água na comunidade, citadas pelos entrevistados, considerando o controle microbiológico da água para o consumo humano (Von Sperling 1996). 
Quadro 1. Indicadores, descritores e escalas de qualificação da sustentabilidade ambiental na dimensão social

\begin{tabular}{|c|c|c|}
\hline Temas & Indicadores & Descritores e escala de qualificação \\
\hline \multirow[b]{2}{*}{$\begin{array}{l}\text { 1. Educação e } \\
\text { formação }\end{array}$} & $\begin{array}{l}\text { a. Pessoas com } 18 \text { anos } \\
\text { ou mais com ensino } \\
\text { fundamental completo }\end{array}$ & $\begin{array}{l}\text { 0: } 0 \% \text { a } 20 \% \text { da comunidade possui ensino fundamental } \\
\text { completo } \\
\text { 1: Mais de } 20 \% \text { a } 40 \% \text { da comunidade possui ensino } \\
\text { fundamental completo } \\
\text { 2: Mais de } 40 \% \text { a } 60 \% \text { da comunidade possui ensino } \\
\text { fundamental completo } \\
\text { 3: Mais de } 60 \% \text { a } 80 \% \text { da comunidade possui ensino } \\
\text { fundamental completo } \\
\text { 4:-Mais de } 80 \% \text { da comunidade possui ensino fundamental } \\
\text { completo }\end{array}$ \\
\hline & $\begin{array}{l}\text { b. Tempo de experiência } \\
\text { na área de atuação e } \\
\text { cursos realizados }\end{array}$ & $\begin{array}{l}\text { Há quanto tempo trabalha na sua atividade econômica } \\
\text { principal? } \\
\text { 0. Até } 1 \text { ano } \\
\text { 1. Mais de } 1 \text { a } 3 \text { anos } \\
\text { 2. Mais de } 3 \text { a } 5 \text { anos } \\
\text { 3. Mais de } 5 \text { a } 10 \text { anos } \\
\text { 4. Mais de } 10 \text { anos } \\
\text { Já participou de cursos de qualificação em sua área de } \\
\text { atuação? Qual tema e em que ano? } \\
\text { 0. Não participou de curso em suas áreas de atuação } \\
\text { 1. Participou de } 1 \text { curso até } 2009 \\
\text { 2. Participou de + de } 1 \text { curso até } 2009 \\
\text { 3. Participou de } 1 \text { curso nos últimos } 5 \text { anos } \\
\text { 4. Participou de + de } 1 \text { curso, sendo um deles pelo menos nos } \\
\text { últimos } 5 \text { ano } \\
\text { Observação: Foram considerados os cursos realizados na } \\
\text { ocupação principal e secundárias. }\end{array}$ \\
\hline \multirow[b]{2}{*}{ 2. Saúde } & $\begin{array}{l}\text { a. Acesso e satisfação } \\
\text { quanto aos serviços de } \\
\text { saúde }\end{array}$ & $\begin{array}{l}\text { Eu e as pessoas de minha casa temos acesso a serviços de } \\
\text { saúde de qualidade sempre que for necessário. } 0-1-2-3- \\
4\end{array}$ \\
\hline & $\begin{array}{l}\text { b. Métodos de } \\
\text { tratamento de água } \\
\text { utilizados }\end{array}$ & $\begin{array}{l}\text { A água consumida para beber e cozinhar é tratada? De que } \\
\text { forma? } \\
\text { 0. Nada } \\
\text { 1. Coa; Resfria; Coa + resfria } \\
\text { 2. Filtra; Coa + filtra } \\
\text { 3. Ferve; Coa + ferve; usa cloro; coa + usa cloro } \\
\text { 4. Filtra + ferve; Filtra + usa cloro; Compra água mineral }\end{array}$ \\
\hline $\begin{array}{l}\text { 3. Segurança } \\
\text { pública }\end{array}$ & $\begin{array}{l}\text { a. Sentimento de } \\
\text { segurança da população } \\
\text { mais vulnerável nos } \\
\text { espaços públicos }\end{array}$ & $\begin{array}{l}\text { Mulheres e crianças podem andar livremente à noite nesta } \\
\text { comunidade. } \\
0-1-2-3-4\end{array}$ \\
\hline
\end{tabular}




\begin{tabular}{|c|c|c|}
\hline Temas & Indicadores & Descritores e escala de qualificação \\
\hline \multirow[t]{4}{*}{ 4. Capital social } & $\begin{array}{l}\text { a. Porcentagem de } \\
\text { pessoas que participam } \\
\text { de grupos e redes }\end{array}$ & $\begin{array}{l}\text { Participa de grupos? Quais? } \\
\text { 0. } 0 \text { a } 20 \% \text { dos entrevistados participam de grupos ou redes } \\
\text { 1. Mais de } 20 \% \text { a } 40 \% \text { dos entrevistados participam de grupos } \\
\text { ou redes } \\
\text { 2. Mais de } 40 \% \text { a } 60 \% \text { dos entrevistados participam de grupos } \\
\text { ou redes } \\
\text { 3. Mais de } 60 \% \text { a } 80 \% \text { dos entrevistados participam de grupos } \\
\text { ou redes } \\
\text { 4. Mais de } 80 \% \text { dos entrevistados participam de grupos ou } \\
\text { redes } \\
\text { Observação: Foi considerada a participação do entrevistado } \\
\text { em pelo menos } 1 \text { grupo ou rede. }\end{array}$ \\
\hline & $\begin{array}{l}\text { b. Facilidade de acesso } \\
\text { à informação e à } \\
\text { comunicação }\end{array}$ & $\begin{array}{l}\text { Eu e as pessoas de minha casa temos acesso fácil às notícias da } \\
\text { região. } \\
0-1-2-3-4\end{array}$ \\
\hline & $\begin{array}{l}\text { c. Grau de cooperação } \\
\text { da comunidade }\end{array}$ & $\begin{array}{l}\text { Quando a estrada fica intransitável, as pessoas cooperam } \\
\text { umas com as outras para resolver o problema. } 0-1-2-3-4\end{array}$ \\
\hline & $\begin{array}{l}\text { d. Grau de } \\
\text { empoderamento da } \\
\text { comunidade }\end{array}$ & $\begin{array}{l}\text { Sinto que tenho poder de auxiliar na melhoria de qualidade } \\
\text { de vida da comunidade. } \\
0-1-2-3-4\end{array}$ \\
\hline \multirow{2}{*}{$\begin{array}{l}\text { 5. Mobilidade e } \\
\text { acessibilidade }\end{array}$} & $\begin{array}{l}\text { a. Facilidade de acesso à } \\
\text { localidades próximas }\end{array}$ & $\begin{array}{l}\text { Em caso de emergência, eu e as pessoas de minha casa temos } \\
\text { como nos deslocar rapidamente para localidades próximas. } \\
0-1-2-3-4\end{array}$ \\
\hline & $\begin{array}{l}\text { b. Condições da estrada } \\
\text { de acesso }\end{array}$ & $\begin{array}{l}\text { As condições da estrada que dá aceso à cidade são adequadas } \\
\text { às necessidades da comunidade. } \quad 0-1-2-3-4\end{array}$ \\
\hline \multirow{2}{*}{ 6. Topofilia } & $\begin{array}{l}\text { a. Elo afetivo da } \\
\text { comunidade com o local } \\
\text { onde residem }\end{array}$ & $\begin{array}{l}\text { Gosto de morar na comunidade. } \\
0-1-2-3-4\end{array}$ \\
\hline & $\begin{array}{l}\text { b. Perspectiva de } \\
\text { crescimento da } \\
\text { população }\end{array}$ & $\begin{array}{l}\text { A comunidade tem tendência a aumentar a população. } 0-1 \text { - } \\
2-3-4\end{array}$ \\
\hline 7. Cultura & $\begin{array}{l}\text { a. Manutenção de } \\
\text { manifestações culturais } \\
\text { locais }\end{array}$ & $\begin{array}{l}\text { A comunidade mantém suas manifestações culturais (festas, } \\
\text { comidas, ...) } \\
0-1-2-3-4 \\
\text { Quais manifestações são mantidas? } \\
\text { Quais manifestações não o são? }\end{array}$ \\
\hline
\end{tabular}

A avaliação da sustentabilidade da dimensão econômica conta com indicadores de renda, de autonomia das famílias na produção de alimentos, das oportunidades de trabalho local, da infraestrutura necessária para que as atividades econômicas continuem se desenvolvendo, tais quais energia elétrica e meios para escoamento das mercadorias, bem como de avaliação do potencial das três principais atividades de geração de renda e subsistência locais: pesca, agricultura e turismo (Quadro 2). 
Quadro 2. Indicadores, descritores e escalas de qualificação da sustentabilidade ambiental na dimensão econômica

\begin{tabular}{|c|c|c|}
\hline Temas & Indicadores & Descritores e escala de qualificação \\
\hline \multirow[t]{3}{*}{ 8. Renda } & $\begin{array}{l}\text { a. Renda familiar per } \\
\text { capita mensal }\end{array}$ & $\begin{array}{l}\text { A estimativa de renda familiar per capita foi calculada a } \\
\text { partir da renda semanal declarada pelos integrantes da } \\
\text { família } x 4 \text { (semanas) + valor da bolsa família mensal } \\
\text { declarada } x 12 \text { (meses) + valor do seguro defeso do robalo x } \\
3 \text { (meses) + valor de aposentadoria declarado x } 13 \text { (meses) } \\
\text { + valor de pensão declarado x } 13 \text { (meses) + valor de outros } \\
\text { benefícios declarados, resultando na renda familiar anual. } \\
\text { Esse valor foi dividido em } 12 \text { (meses) e então, dividido pelo } \\
\text { número de membros da família. } \\
\text { 0. até } R \$ 77,00 \text { per capita } \\
\text { 1. } R \$ 77,01 \text { a } R \$ 154,00 \text { per capita } \\
\text { 2. } R \$ 154,01 \text { a } \$ 362,00 \\
\text { 3. } R \$ 362,01 \text { a } R \$ 724,00 \\
\text { 4. Mais de } R \$ 724,00^{2}\end{array}$ \\
\hline & b. Estabilidade da renda & $\begin{array}{l}\text { A renda total das pessoas dessa casa tem aumentado neste } \\
\text { ano, comparando ao ano anterior. } \\
0-1-2-3-4 \\
\text { Caso } 0,1 \text { ou } 2 \text {, a renda das pessoas dessa casa tem se mantido } \\
\text { a mesma, em comparação ao ano anterior. } \\
0-1-2-3-4\end{array}$ \\
\hline & $\begin{array}{l}\text { c. Satisfação das } \\
\text { necessidades básicas }\end{array}$ & $\begin{array}{l}\text { A renda das pessoas dessa casa consegue satisfazer nossas } \\
\text { necessidades básicas de alimentação e moradia. } 0-1-2-3 \\
-4\end{array}$ \\
\hline $\begin{array}{l}\text { 9. Oportunidade } \\
\text { de trabalho }\end{array}$ & $\begin{array}{l}\text { a. Oportunidade de } \\
\text { trabalho local para } \\
\text { jovens e mulheres }\end{array}$ & $\begin{array}{l}\text { Os jovens encontram oportunidade de trabalho na } \\
\text { comunidade. } 0-1-2-3-4 \\
\text { As mulheres encontram oportunidade de trabalho na } \\
\text { comunidade. } 0-1-2-3-4\end{array}$ \\
\hline $\begin{array}{l}\text { 10. Energia } \\
\text { elétrica }\end{array}$ & $\begin{array}{l}\text { a. Satisfação quanto } \\
\text { à oferta de energia } \\
\text { elétrica }\end{array}$ & $\begin{array}{l}\text { Estou satisfeito com a oferta de energia elétrica em minha } \\
\text { casa. } \\
0-1-2-3-4\end{array}$ \\
\hline $\begin{array}{l}\text { 11. Escoamento } \\
\text { da produção }\end{array}$ & $\begin{array}{l}\text { a. Facilidade de } \\
\text { transporte de } \\
\text { mercadorias }\end{array}$ & $\begin{array}{l}\text { O transporte de mercadorias para as cidades mais próximas } \\
\text { está acessível sempre que necessário. } 0-1-2-3-4\end{array}$ \\
\hline $\begin{array}{l}\text { 12. Produção } \\
\text { local }\end{array}$ & $\begin{array}{l}\text { a. Produtos alimentícios } \\
\text { consumidos, } \\
\text { produzidos por cada } \\
\text { família }\end{array}$ & $\begin{array}{l}\text { Os alimentos consumidos nessa casa são produzidos por nós } \\
\text { (pelas pessoas dessa casa). } \\
0-1-2-3-4\end{array}$ \\
\hline $\begin{array}{l}\text { 13. Potencial } \\
\text { da atividade } 1 \\
\text { (pesca) }\end{array}$ & $\begin{array}{l}\text { a. Aumento da } \\
\text { quantidade de } \\
\text { pescadores e } \\
\text { importância da pesca } \\
\text { para a comunidade }\end{array}$ & $\begin{array}{l}\text { A quantidade de pescadores vem aumentando nos últimos } \\
\text { anos na comunidade. } \\
0-1-2-3-4 \\
\text { A pesca é uma atividade importante para a comunidade. } 0 \text { - } \\
1-2-3-4\end{array}$ \\
\hline
\end{tabular}

$2 \mathrm{O}$ valor do salário mínimo durante a realização desse estudo era de $\mathrm{R} \$ 724,00$, em torno de US\$ 323,56 . 


\begin{tabular}{|l|l|l|}
\hline \multicolumn{1}{|c|}{ Temas } & \multicolumn{1}{c|}{ Indicadores } & \multicolumn{1}{c|}{ Descritores e escala de qualificação } \\
\hline $\begin{array}{l}\text { 14. Potencial } \\
\text { da atividade 2 } \\
\text { (agricultura) }\end{array}$ & $\begin{array}{l}\text { a. Aumento da } \\
\text { quantidade de } \\
\text { agricultores e } \\
\text { importância da } \\
\text { agricultura para a } \\
\text { comunidade }\end{array}$ & $\begin{array}{l}\text { A quantidade de agricultores vem aumentando nos últimos } \\
\text { anos na comunidade. } \\
0-1-2-3-4\end{array}$ \\
\hline & $\begin{array}{l}\text { A agricultura é uma atividade importante para a } \\
\text { comunidade. } 0-1-2-3-4\end{array}$ \\
$\begin{array}{l}\text { 15. Potencial } \\
\text { da atividade 3 } \\
\text { (turismo) }\end{array}$ & $\begin{array}{l}\text { quantidade de } \\
\text { profissionais do } \\
\text { turismo, de turistas e } \\
\text { importância do turismo } \\
\text { para a comunidade }\end{array}$ & $\begin{array}{l}\text { A quantidade de pessoas que vivem do turismo na } \\
\text { comunidade vem aumentando nos últimos anos. } 0-1-2- \\
3-4 \\
\text { A quantidade de turistas que visitam a comunidade vem } \\
\text { aumentando nos últimos anos. } \\
0-1-2-3-4 \\
\text { O turismo é uma atividade importante para a comunidade. } \\
0-1-2-3-4\end{array}$ \\
\hline
\end{tabular}

*Apenas os que tinham a pesca, a agricultura e/ou o turismo como uma das três ocupações declaradas responderam esses itens, respectivamente.

$\mathrm{Na}$ dimensão ecológica da sustentabilidade, avaliou-se a percepção da comunidade quanto ao estado de conservação dos recursos pesqueiros, da vegetação e do solo e dos atrativos turísticos, escolha norteada pelo viés do materialismo histórico, considerando as atividades econômicas mais relevantes (Quadro 3).

A análise da conservação dos recursos pesqueiros foi orientada pela percepção da comunidade quanto ao aumento ou diminuição das duas espécies de peixe mais valorizadas comercialmente, bem como a avaliação de quanto as práticas de pesca realizadas no local estão em conformidade com a legislação vigente. Já os recursos utilizados na atividade agrícola foram avaliados em termos de percepção quanto ao uso do fogo nas propriedades agrícolas e quanto à conservação da mata ciliar do entorno da lagoa, bem como das nascentes e cursos d'água que se localizam no interior das propriedades rurais. Ainda, a avaliação da conservação dos atrativos turísticos levou em conta a percepção da comunidade quanto à conservação dos três atrativos mais visitados pelos turistas, indicados pelos barqueiros locais.

Optou-se por inserir os indicadores de saneamento na dimensão ecológica visto o potencial de poluição do ecossistema local quando da ausência de saneamento básico. A definição da escala de sustentabilidade dos resíduos sólidos domésticos considerou as formas de destinação existentes no local e estudos sobre a temática, a partir da Política Nacional de Resíduos Sólidos (Brasil 2010). Elaborou-se uma escala de qualificação que considerou a reutilização, a recuperação, a venda ou a doação do resíduo como destinações corretas. Esse fato se deu uma vez que, apesar de haver serviço público de coleta de resíduos no local, não há coleta seletiva, e a disposição final dos resíduos acontece em um aterro controlado. Os aterros controlados são inadequados, principalmente pelo potencial poluidor representado pelo chorume, que não é coletado e tratado neste tipo de aterro (IBGE 2012). 
Quadro 3. Indicadores, descritores e escalas de qualificação da sustentabilidade ambiental na dimensão dos recursos naturais.

\begin{tabular}{|c|c|c|}
\hline Temas & Indicadores & Descritores e escala de qualificação \\
\hline \multirow{2}{*}{$\begin{array}{l}\text { Conservação } \\
\text { dos recursos } \\
\text { pesqueiros }\end{array}$} & $\begin{array}{l}\text { a. Aumentos das } \\
\text { espécies de peixes } \\
\text { mais valorizadas } \\
\text { comercialmente }^{\star}\end{array}$ & $\begin{array}{l}\text { A quantidade de robalo vem aumentando nos últimos cinco } \\
\text { anos. } 0-1-2-3-4 \\
\text { A quantidade de carapeba vem aumentando nos últimos cinco } \\
\text { anos. } 0-1-2-3-4\end{array}$ \\
\hline & $\begin{array}{l}\text { b. Práticas de pesca em } \\
\text { conformidade com a } \\
\text { legislação* }^{*}\end{array}$ & $\begin{array}{l}\text { A pesca vem sendo feita de forma correta (seguindo a } \\
\text { legislação, respeito ao período de defeso, etc). } 0-1-2-3-4\end{array}$ \\
\hline \multirow[t]{2}{*}{$\begin{array}{l}\text { Conservação } \\
\text { da vegetação e } \\
\text { do solo }\end{array}$} & $\begin{array}{l}\text { a. Estado de } \\
\text { conservação da mata } \\
\text { ciliar }\end{array}$ & $\begin{array}{l}\text { De zero a } 4 \text { que nota o(a) senhor(a) daria para o estado de } \\
\text { conservação da vegetação do entorno da Lagoa Encantada? } 0 \text { - } \\
1-2-3-4 \\
\text { Há rios, córregos, lagos, fontes de água na propriedade? } \\
\text { Sim ( ) Não } \\
\text { SE SIM, de zero a } 4 \text { que nota o(a) senhor(a) daria para o estado } \\
\text { de conservação da vegetação do entorno (mata ciliar) dessas } \\
\text { fontes d'água da propriedade. }{ }^{* *} \\
0-1-2-3-4 \\
\text { Observação: Muito ruim }(0) \text { a muito bom }(4)\end{array}$ \\
\hline & $\begin{array}{l}\text { b. Estado de } \\
\text { conservação do solo* }\end{array}$ & $\begin{array}{l}\text { Nos últimos cinco anos têm ocorrido queima para limpeza da } \\
\text { roça nas propriedades do entorno da Lagoa Encantada. }{ }^{* \star} 0-1 \\
-2-3-4\end{array}$ \\
\hline $\begin{array}{l}\text { Conservação } \\
\text { dos atrativos } \\
\text { turísticos }\end{array}$ & $\begin{array}{l}\text { a. Estado de } \\
\text { conservação dos } \\
\text { principais atrativos } \\
\text { turísticos }\end{array}$ & $\begin{array}{l}\text { A Lagoa Encantada está conservada } \\
0-1-2-3-4 \\
\text { A Cachoeira Véu da Noiva está conservada. } \\
0-1-2-3-4 \\
\text { A Cachoeira do Apepique está conservada. } \\
0-1-2-3-4\end{array}$ \\
\hline $\begin{array}{l}19 . \\
\text { Saneamento } \\
\text { Básico }\end{array}$ & $\begin{array}{l}\text { a. Destino do } \\
\text { esgotamento sanitário }\end{array}$ & $\begin{array}{l}\text { Onde o esgoto do banheiro (ou sanitário) desta casa é lançado? } \\
0 . \text { Não há banheiro na casa } \\
\text { 1. Corpos d'água superficiais ou vala (rios, córregos d'água, } \\
\text { lagoa ou a céu aberto no terreno) } \\
\text { 2. Fossa negra } \\
\text { 3. Fossa séptica } \\
\text { 4. Recebe tratamento (próprio ou público) }\end{array}$ \\
\hline
\end{tabular}




\begin{tabular}{|c|c|c|}
\hline $\begin{array}{l}19 . \\
\text { Saneamento } \\
\text { Básico }\end{array}$ & $\begin{array}{l}\text { b. Destino dos resíduos } \\
\text { sólidos domésticos }\end{array}$ & 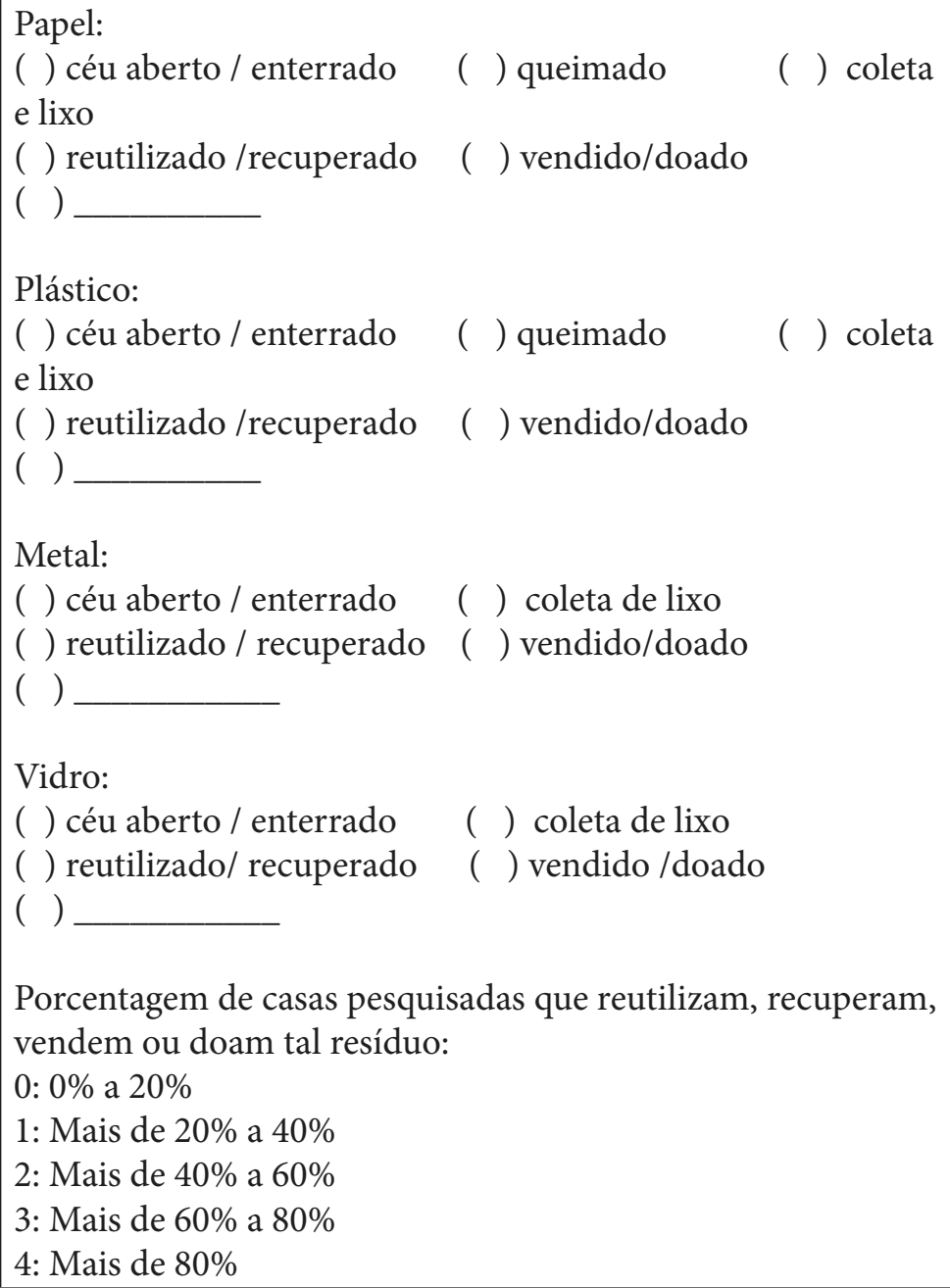 \\
\hline
\end{tabular}

*Apenas os que tinham a pesca, a agricultura e/ou o turismo como uma das três ocupações declaradas responderam esses itens, respectivamente.

** Escala invertida, sendo o maior valor indicativo de menor sustentabilidade. No processo de computação dos dados, tais valores foram reajustados para que os maiores valores representem maior sustentabilidade.

Cada dimensão, tema e indicador possuem o mesmo grau de importância na composição do Índice de Sustentabilidade Ambiental da Comunidade (ISAC). Essa escolha foi feita visando à criação de um sistema fácil de ser compreendido pela comunidade e de ser replicado.

A pontuação de cada indicador é resultado da soma de pontos obtidos, dividida pelo número de respondentes daquele item. O mesmo processo é utilizado com cada tema, cujo resultado deriva da soma dos pontos dos indicadores, dividido pela quantidade de indicadores do respectivo tema. O ISAC é composto pela média aritmética simples do resultado de cada uma das dimensões e é apresentado sob a forma de índice, variando de zero a um, no qual quanto mais próximo de um, mais alto o nível de sustentabilidade, de acordo com escala do Quadro 4. 
Quadro 4. Escala de sustentabilidade

\begin{tabular}{|c|c|}
\hline Escala de Sustentabilidade & $\begin{array}{c}\text { Parâmetros considerados } \\
\text { (Escala de 0 a 1) }\end{array}$ \\
\hline Sustentabilidade alta & $1,000-0,800$ \\
\hline Sustentabilidade boa & $0,799-0,650$ \\
\hline Sustentabilidade média & $0,649-0,500$ \\
\hline Sustentabilidade baixa & $0,499-0,300$ \\
\hline Sustentabilidade crítica & $0,299-0,000$ \\
\hline
\end{tabular}

As respostas dos formulários aplicados pela pesquisadora na comunidade foram inseridas em planilhas, codificadas, tabuladas e analisadas com o uso da estatística descritiva, via elaboração de frequências e percentuais. Para tanto, utilizou-se o Excel Office 2013, programa usado também na confecção dos gráficos aqui apresentados.

\section{Resultados e Discussões}

\section{Caracterização da área de estudo}

A Lagoa Encantada, conhecida também como Lagoa do Itaípe ou do Taipe, está localizada no distrito de Castelo Novo, a 34 km da sede do município de Ilhéus e é parte da Bacia Hidrográfica do Rio Almada, comunicando-se com o respectivo rio através do Canal de Itaípe (Andrade 2003). A região integra a Área de Proteção Ambiental (APA) da Lagoa Encantada e do Rio Almada, a Reserva da Biosfera da Mata Atlântica, bem como o Mini-Corredor Ecológico Esperança Conduru, sendo considerada uma região prioritária para a conservação da biodiversidade (Bahia 2003; RBMA 2014).

A população da APA da Lagoa Encantada e do Rio Almada tem na pesca artesanal e na agricultura cacaueira e de subsistência suas principais atividades econômicas (Silva et al. 2007). Além dessas, os moradores da Vila de Areias, comunidade de aplicação da pesquisa, têm na atividade turística uma importante fonte de renda (Bahia 2002).

A Vila de Areias serviu durante muito tempo de abrigo aos pescadores na época das enchentes do Rio Almada. Em 1980, a área onde a vila se localiza, foi escolhida pelas lideranças e pela Prefeitura Municipal de Ilhéus como assentamento definitivo para os desabrigados do povoado de Laranjeiras (Bahia 1996). Na ocasião, foi desapropriada uma área de 20 ha da Fazenda Areias e demarcados lotes padrão de 10 × 20 metros, agrupados em quadras, sem projeto urbanístico ou planejamento da ocupação. Aquele momento inicia a expansão urbana sobre a Lagoa Encantada, sem, entretanto, nenhuma infraestrutura de saneamento, mobilidade ou urbanismo (Bahia 1996). Posteriormente, foi agregado à área inicial um parcelamento informal, ampliando a área urbana da vila (Bahia 2002).

Quanto à infraestrutura básica e às instalações físicas localizadas na Vila de Areias, tem-se: uma escola, com atendimento até o $5^{\circ}$ ano (antiga $4^{\text {a }}$ série); um posto de saúde que se encontra 
inativo; as sedes das igrejas Católica, Assembleia de Deus e Nova Canaã; os espaços da Associação de Moradores local e da Casa Arte da Criança, organização social que realiza ações de arte e cultura com as crianças da comunidade; um campo de futebol; rede de energia elétrica; sistema de abastecimento de água; acesso rodoviário a partir da BA 001 e hidroviário a partir do Rio Almada; transporte público disponível quatro vezes ao dia, abrangendo o trecho entre a Vila de Areias e o centro de Ilhéus, e coleta de resíduos sólidos duas vezes ao mês. Já, como infraestrutura de apoio ao turismo, há: três restaurantes, dois mercados/mercearias, um centro de atendimento aos turistas (inativo), uma pousada e outra em construção.

No entorno imediato da Lagoa Encantada encontram-se, ainda, as fazendas Ponta Grossa, Inhaúpe, Ilha da Alfândega, Cutiatá, Parafuso e São Paulo. Seu principal produto agrícola é o cacau, sendo que algumas desenvolvem também a pecuária. Parte da Fazenda São Paulo, uma das maiores propriedades do entorno, integra a Reserva Particular do Patrimônio Natural (RPPN) ${ }^{3}$ Salto Apepique, na qual estão localizados os atrativos turísticos mais visitados da Lagoa Encantada como o Salto do Apepique e a Cachoeira Véu da Noiva.

Estima-se um total de 521 habitantes moradores do entorno da Lagoa Encantada, considerando o total de casas habitadas e a média de 3,3 moradores por residência encontrada na pesquisa.

\section{Sustentabilidade ambiental da comunidade do entorno da Lagoa Encantada}

A avaliação da sustentabilidade ambiental da comunidade do entorno da Lagoa Encantada demonstrou que, dentre as três dimensões estudadas, a econômica é a que se encontra em melhores condições, podendo ser considerada como de média sustentabilidade $(0,555)$. Já as dimensões social $(0,479)$ e dos recursos naturais $(0,406)$ foram classificadas como de baixa sustentabilidade, resultando em um ISAC de baixa sustentabilidade $(0,480)$, conforme Figura 2.

Figura 2. Avaliação da sustentabilidade ambiental da comunidade de entorno da Lagoa Encantada, Ilhéus, Bahia.

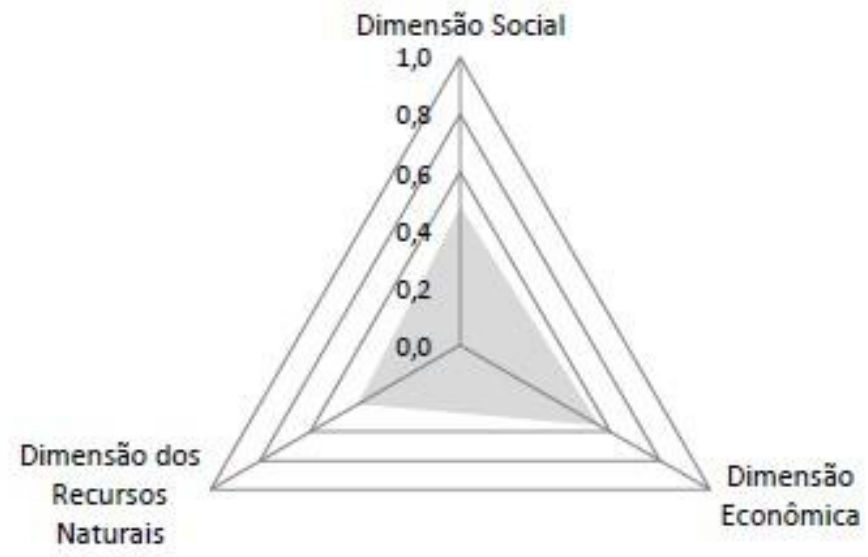

3 A Reserva Particular do Patrimônio Natural é uma Unidade de Conservação de propriedade privada. Ela é criada pela manifestação voluntária do proprietário, o qual tem como vantagens, além da garantia de conservação da beleza cênica e/ou de riqueza biológica de sua área, receber benefícios econômicos, mais especificamente por meio do turismo e do ICMS ecológico, bem como tem garantida a perpetuidade da posse da área (Santos e Schiavetti 2008). 
Em relação à dimensão social, o bem-estar humano está comprometido com o resultado insatisfatório dessa dimensão. $\mathrm{O}$ desenvolvimento endógeno é dificultado uma vez que o acesso à educação é bastante deficitário e o capital social local frágil, o que impede o empoderamento da população. A precariedade da mobilidade e acessibilidade impacta sobremaneira o acesso à educação e frequência à escola, uma vez que os professores se deslocam diariamente à comunidade, e os alunos do $4^{\circ}$ ciclo em diante precisam ir à sede do município para continuarem seus estudos (Figura 3 ).

Figura 3. Avaliação da sustentabilidade da dimensão social.

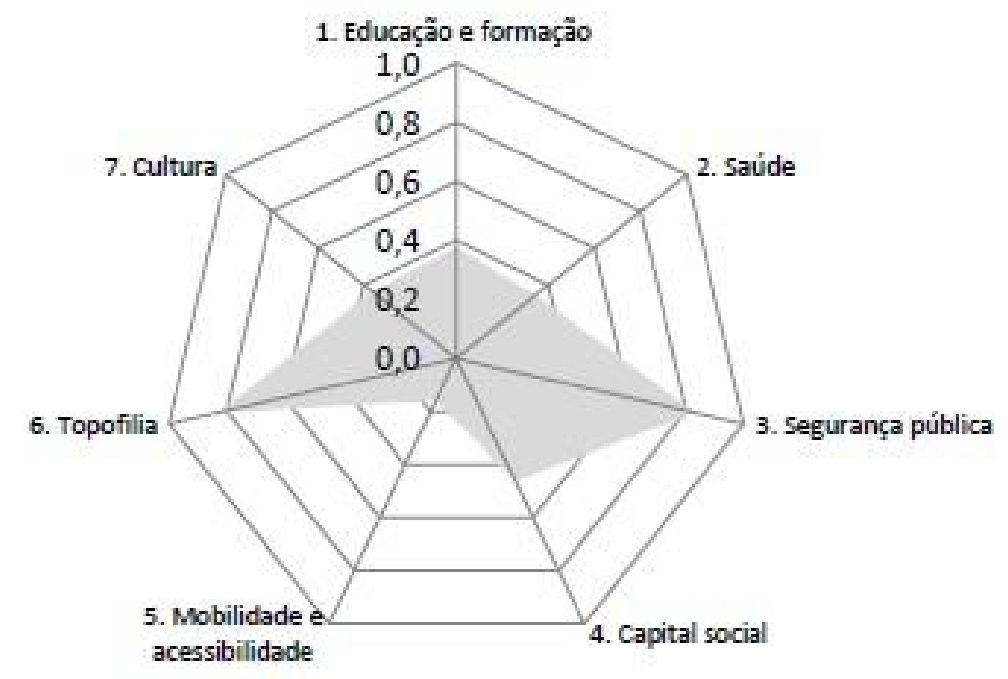

Em relação ao capital social, o indicador que mais impactou negativamente no resultado desse tema foi o "grau de cooperação da comunidade". Há falta de cooperação entre os habitantes para resolver problemas coletivos. Alguns respondentes relataram serem sempre as mesmas pessoas que participam das ações coletivas, ficando grande parte da comunidade ausente desses processos.

Os temas "segurança pública" e "topofilia" foram os que obtiveram melhor classificação na dimensão social. A tranquilidade, o baixo índice de violência e a paz foram os aspectos mais citados como o que mais agrada os moradores da Lagoa Encantada. A ligação afetiva da comunidade com o local de residência mostrou-se bastante forte. Assim, apesar das carências e dificuldades apontadas, a grande maioria dos entrevistados $(92,1 \%)$ gosta de morar na comunidade.

Em se tratando da sustentabilidade da dimensão econômica, a renda familiar per capita parece ser suficiente para garantir as necessidades básicas da família e, portanto, a sua reprodução no tempo. Contudo, constata-se que há falta de oportunidades de trabalho na região, causando a migração, especialmente dos jovens, para outros centros (Figura 4). Apesar da migração, a comunidade vê perspectiva de crescimento da população local, o que pode ser explicado por fatores como o elo afetivo dos moradores com o local e a tranquilidade/segurança, citada como o que mais agrada os habitantes da comunidade. 
Figura 4. Avaliação da sustentabilidade da dimensão econômica.

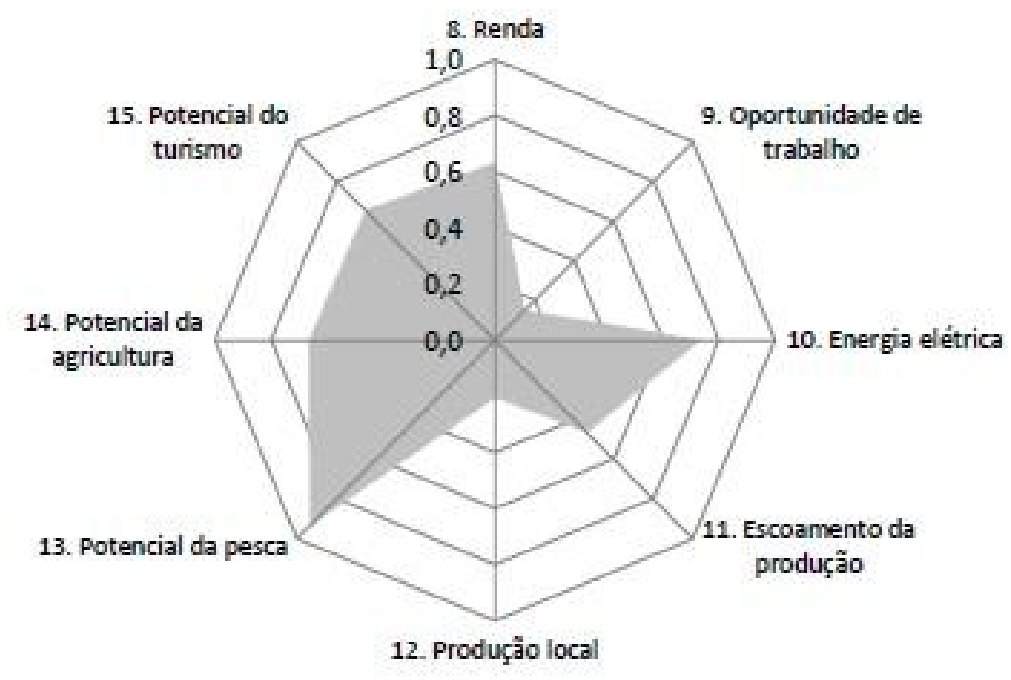

Ainda, a baixa incidência dos que utilizam o quintal de casa ou sua propriedade rural para produzir alimentos ou criar animais para consumo da família, bem como a precariedade das condições de escoamento da produção local, uma vez que parte da produção é comercializada externamente, impactaram negativamente no resultado dessa dimensão.

Dentre as atividades econômicas avaliadas, a pesca desponta como a de maior potencial. Houve um aumento na quantidade de pescadores nos últimos cinco anos e a atividade é percebida como de extrema importância para a comunidade. A atividade agrícola, por sua vez, parece não ter atraído mais trabalhadores nos últimos cinco anos. A estagnação de profissionais dedicados à atividade pode ser atribuída, entre outros fatores, à perda da importância da cacauicultura em âmbito regional. Por sua vez, o turismo é avaliado como a atividade de menor potencial no local, principalmente em decorrência da percepção da diminuição da quantidade de turistas que visitaram a Lagoa Encantada nos cinco últimos anos. Alguns dos fatores que podem ser relacionadas ao resultado são as condições da estrada de acesso, a falta de uma melhor estrutura de receptivo e de produtos turísticos regionais que incluam os atrativos da Lagoa Encantada no roteiro, bem como o aumento da competitividade de outros destinos ecoturísticos na região.

Quanto aos recursos naturais locais, a avaliação indica que os mesmos não estão sendo conservados eficientemente, apesar da área estar inserida em Unidades de Conservação e ser prioritária para conservação da biodiversidade, sobretudo os recursos pesqueiros, afetando o equilíbrio dos ecossistemas locais (Figura 5). Sendo a pesca a principal fonte de renda e de subsistência, o desequilíbrio no ecossistema aquático, a médio e longo prazo, pode comprometer a economia e fragilizar ainda mais o ambiente da comunidade. Os principais motivos para a crítica condição dos recursos pesqueiros são a pesca predatória, a sobrepesca e a existência de espécies exóticas na lagoa. A introdução de espécies exóticas pode resultar em perda de biodiversidade, ao incluir a introdução de parasitas e promover a competição biológica com espécies nativas (Rocha, 2008). 
Figura 5. Avaliação da sustentabilidade da dimensão dos recursos naturais.

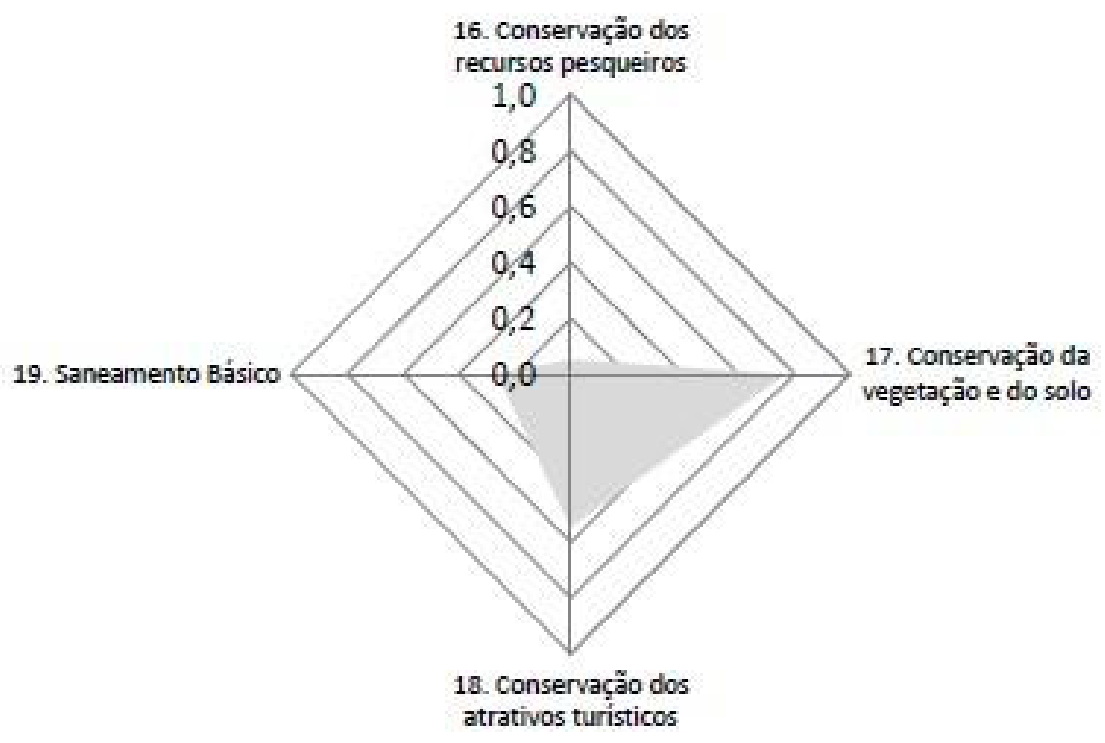

Na Lagoa Encantada, a pesca é permitida com o uso do anzol e da rede de espera, mas proibida na modalidade de mergulho, bem como com o uso de tarrafa, de rede de arrasto, ou da batida para rede de espera (Sudepe 1982). Além disso, de 15 de maio a 31 de julho, a pesca do Robalo é proibida devido a seu período de defeso. Entretanto, a maior parte dos pescadores (81\%) tem ciência de que a pesca no local é feita de forma incorreta. A falta de fiscalização dos órgãos públicos municipais, estaduais e federais foi citada como o principal motivo para a continuidade dessas práticas.

O tema "saneamento básico" foi avaliado como de sustentabilidade crítica. O esgotamento sanitário de 77,4\% das residências do entorno da Lagoa é despejado em fossas negras. Nas demais residências, ou não há banheiro $(17,4 \%)$ ou as águas negras são despejadas em corpos d'água superficiais ou valas $(5,2 \%)$. Um sistema precário de esgotamento sanitário causa sérios impactos nos ecossistemas locais, como o decréscimo dos teores de oxigênio dissolvido nos cursos d'água locais e a eutrofização (Von Sperling 1996). Além disso, a precária destinação dos resíduos sólidos, além de poluir os recursos naturais, também tem impacto visual, o que é bastante negativo no que tange à atratividade turística local.

\section{Considerações finais}

A aplicação do modelo de avaliação da sustentabilidade ambiental na comunidade do entorno da Lagoa Encantada evidencia a urgência de ações para a melhoria do cenário local, tendo em vista a baixa sustentabilidade ambiental identificada. Tal mudança depende, sobretudo, de melhores condições de mobilidade e acessibilidade, da ampliação das oportunidades de trabalho na região, de ações de conservação dos recursos pesqueiros e da existência de saneamento básico. Nesse sentido, é imprescindível o fortalecimento do capital social, para que a comunidade busque soluções coletivas

4 Ao contrário das fossas negras, nas fossas sépticas o esgoto e os dejetos passam por um processo de tratamento ou decantação, no qual a parte líquida é absorvida pelo próprio terreno ou canalizada para um desaguadouro do local, região ou município (IBGE 2011). 
para as vulnerabilidades locais. Ainda, faz-se necessário o investimento em ações de educação ambiental e equipe para fiscalização da legislação ambiental vigente, bem como em novas atividades de geração de renda que ajudem a diminuir a pressão sobre os recursos naturais como os pesqueiros.

Os resultados obtidos com a avaliação realizada podem orientar, de forma precisa, os gestores públicos e a própria comunidade quanto às medidas e ações necessárias à melhoria das condições verificadas. Além disso, considerar as principais atividades que permitem a reprodução da vida material e social local na construção do modelo de avalição foi imprescindível para a escolha de indicadores coerentes com a dinâmica de vida de uma comunidade altamente dependente dos recursos naturais para sua sobrevivência.

Diante do exposto, acredita-se que o modelo de avaliação utilizado é adequado para dimensionar a sustentabilidade das condições sociais, econômicas e dos recursos naturais de comunidades com características semelhantes à pesquisada: comunidades ribeirinhas que têm a pesca artesanal, a agricultura familiar e o turismo como principais atividades de geração de renda e subsistência.

Além disso, o sistema de indicadores elaborado tem como diferencial o emprego de uma metodologia que busca absorver os aspectos positivos das abordagens bottom up e top-down ao envolver a comunidade na discussão dos indicadores e instrumento de coleta de dados, selecionados a partir da literatura, tornando-o sensível às variáveis do contexto local, sem perder a objetividade e a universalidade do mesmo.

Dentre os desafios verificados durante a elaboração do presente instrumento, citam-se a simplificação do sistema de indicadores para a compreensão dos envolvidos, sem perder a qualidade na medição; o cuidado no alinhamento de expectativas em relação ao estudo, tendo em vista o envolvimento da comunidade local na validação do sistema e instrumento de coleta de dados e a continuidade da aplicação de instrumentos como o em questão, visto serem alimentados por dados primários, demandando investimento de tempo e recursos financeiros para a coleta de informações. Ainda, compreender em que medida e como um indicador influencia o resultado dos demais é outro desafio posto. A interação do ser humano com o meio onde vive acontece de forma orgânica e complexa, sendo importante avançar cada vez mais no estudo dessas correlações.

Por fim, ressalta-se que a análise da sustentabilidade ambiental de comunidades por meio da utilização de indicadores, possibilita tornar tangíveis conceitos abstratos como os de sustentabilidade ambiental e, assim, incentivar novas formas de interação entre o ser humano e seu ambiente, considerando uma alta qualidade de vida para as comunidades humanas, bem como a conservação dos recursos naturais locais.

\section{Agradecimentos}

Agradecemos à comunidade do entorno da Lagoa Encantada, em especial à Odete Oliveira de Sá Menezes e família pelo gentil acolhimento da pesquisadora em sua residência durante o período de campo desse estudo, bem como ao Conselho Nacional de Desenvolvimento Científico e Tecnológico (CNPq) pela bolsa de estudos concedida à primeira autora (processo $n^{\circ}$. 130781/2013-4), que possibilitou dedicação integral ao programa de pós-graduação e a operacionalização da presente pesquisa. 
Participação dos autores: LB - Participou de todas as fases do projeto, autora da dissertação de mestrado que gerou os dados do manuscrito; SPT - coorientador da dissertação de mestrado, participou de todas as fases do projeto e da revisão final do artigo; WFM - orientador da dissertação de mestrado, participou de todas as fases do projeto e da revisão final do artigo.

Aprovação ética: Aprovação ética e licenças: aprovada no Comitê de Ética em Pesquisa (CEP) da Universidade Estadual de Santa Cruz (UESC), pelo parecer nº 644.967.

Disponibilidade dos dados: dados não disponíveis em nenhuma base.

Fomento: LB recebeu bolsa do Conselho Nacional de Desenvolvimento Científico e Tecnológico (CNPq) (processo no. 130781/2013-4).

Conflito de interesses: os autores declaram não haver conflito de interesses.

\section{Referências}

Andrade ALM de. 2007. Indicadores de sustentabilidade na Reserva de Desenvolvimento Sustentável do Piranha, Manacapuru, Amazonas, Brasil. Acta Amazônica 37(3):401-412. https://doi.org/10.1590/S0044-59672007000300011

Andrade MP. 2003. Ilhéus: Passado e Presente. 2a ed. Ilhéus: Editus, 143 p.

Bahia. 2003. Decreto Estadual n 8.650 de 22 de setembro de 2003, altera a poligonal e a denominação da Área de Proteção Ambiental - APA da Lagoa Encantada, no Município de Ilhéus, e dá outras providências.

Bahia. 2002. Plano de Referência Urbanístico Ambiental - Vila Turística Areias. Salvador: Secretaria da Cultura e Turismo, 27 p.

Bahia. 1996. Plano de Manejo da Área de Proteção Ambiental da Lagoa Encantada. Salvador: Empresa de Turismo da Bahia, 273 p.

Barreto RCS, Ahmad SK, Lima PVPS. 2005. Sustentabilidade dos assentamentos do município de Caucaia - CE. Revista de Economia e Sociologia Rural 43(2):225-247. https://doi.org/10.1590/S0103-20032005000200002

Brasil. 2010. Lei n 2.305 de 2 de agosto de 2010, institui a Política Nacional de Resíduos Sólidos, altera a Lei no 9.605 e dá outras providências.

CMMAD. Comissão Mundial sobre Meio Ambiente e Desenvolvimento. 1991. Nosso futuro comum. 2a ed. Tradução de Our Common Future. 1a ed. 1988. Rio de Janeiro: Editora da Fundação Getúlio Vargas, 226 p.

Diegues AC. 2003. Sociedades e Comunidades Sustentáveis. São Paulo: Nupaub - USP. Disponível em: < http://nupaub. fflch.usp.br/sites/nupaub.fflch.usp.br/files/color/comsust.pdf>. Acesso em: 18 ago 2014.

Foladori G. 2002. Avanços e limites da sustentabilidade social. Revista Paranaense de Desenvolvimento 102:103-113.

Gadotti M. 2000. Pedagogia da terra. 2a ed. São Paulo: Peirópolis, 224 p.

Gallopín G. 2003. A systems approach to sustainability and sustainable development. Santiago, Chile, March, 42 p.

Gil AC. 2008. Métodos e técnicas de pesquisa social. 6a ed. São Paulo: Atlas, 220 p.

Grootaert C, Narayan D, Jones VN, Woolcock M. 2003. Questionário Integrado para Medir Capital Social (QI-MCS). Banco Mundial: Grupo Temático sobre Capital Social, 73 p.

Grzebieluka D. 2012. Por uma Tipologia das Comunidades Tradicionais Brasileiras. Revista Geografar. Curitiba 7(1):116-137. http://dx.doi.org/10.5380/geografar.v7i1.21757 
IBGE. Instituto Brasileiro de Geografia e Estatística. 2011. Censo Demográfico 2010: Características da População e dos Domicílios - Resultados do Universo. Rio de Janeiro: IBGE, 270 p.

IBGE. Instituto Brasileiro de Geografia e Estatística. 2012. Indicadores de Desenvolvimento Sustentável: Brasil 2012. Rio de Janeiro: IBGE, $350 \mathrm{p}$.

Loureiro CF, Azaziel, M, Franca N (org). 2003. Educação ambiental e gestão participativa em unidades de conservação. Rio de Janeiro: Ibase: Ibama, 44 p.

Marx K. 1977. The German Ideology. In: Mclellan D. Karl Marx: Selected Writings. New York: Oxford University Press, p. $159-168$.

Malheiros TF, Coutinho SMV, Phillipi JRA. 2012. Indicadores de sustentabilidade: uma abordagem conceitual. In: Malheiros TF, Philippi JRA. (Ed.) Indicadores de Sustentabilidade e Gestão Ambiental. Barueri: Manole, p. 30-76.

Mauerhofer V. 2008. 3-D Sustainability: An approach for priority setting in situation of conflicting interests towards a Sustainable Development. Ecological Economics 64(3):496-506. DOI: https://doi.org/10.1016/j.ecolecon.2007.09.011.

Mckenzie S. 2004. Social Sustainability: Towards Some Definitions. South Australia: Hawke Research Institute University of South Australia Magill, 31 p.

Montibeller GF. 2004. O mito do desenvolvimento sustentável. 2a ed. Florianópolis: Editora da UFSC, 316 p.

Neves J. 2004. Ribeirinhos, Desenvolvimento e a Sustentabilidade Possível. Presença Revista de Educação, Cultura e Meio Ambiente 28(8):1-13.

Pelinski A, Ahrens DC, Milléo RDS, Zemke E, Benassi DA, Richter AS. 2006. Auto-consumo: sua relevância na sustentabilidade da agricultura familiar. In: IV Congresso Brasileiro de Agroecologia. Belo Horizonte: EMATER-MG, p. 40-44.

Putnam R. 2006. Comunidade e Democracia: a experiência da Itália moderna. 5a ed. Rio de Janeiro: Editora FGV, 260 p.

Rabelo LS, Lima PVPS. 2007. Indicadores de Sustentabilidade: a possibilidade de mensuração do desenvolvimento sustentável. Revista Eletrônica do Prodema 1(1):55-76.

Rayén Quiroga M. 2001. Indicadores de sostenibilidad ambiental y de desarrollo sostenible: estado del arte y perspectivas. Chile: División de Medio Ambiente y Asentamientos Humanos, 124 p.

Reed MS, Fraser EDG, Dougill AJ. 2006. An adaptive learning process for developing and applying sustainability indicators with local communities. Ecological Economics 59:406-418. https://doi.org/10.1016/j.ecolecon.2005.11.008

RBMA. Reserva da Biosfera da Mata Atlântica. Texto Síntese. Disponível em: <http://www.rbma.org.br/rbma/rbma_1_ textosintese.asp>. Acesso em: 8 abr 2014.

Ribeiro MA. 2012. O rio como elemento da vida em comunidades ribeirinhas. Revista de Geografia - UFPE, 29(2):83-88. https://doi.org/10.51359/2238-6211.2012.228983

Rocha GRA. 2008. The introduction of the African catfish Clariasgariepinus (Burchell, 1822) into Brazilian inland waters: a growing threat. Neotropical Ichthyology 6(4):693-696. https://doi.org/10.1590/S1679-62252008000400020

Rodrigues A, Tommasino H, Foladori G, Gregorczuk A. 2003. É correto pensar a sustentabilidade em nível local? Uma análise metodológica de um estudo de caso em uma Área de Proteção Ambiental no litoral sul do Brasil. Ambiente \& Sociedade 6(1):109-127. https://doi.org/10.1590/S1414-753X2003000200007

Sachs I. 2004. Desenvolvimento: includente sustentável, sustentado. Rio de Janeiro: Garamond, 151 p.

Santos MS, Schiavetti A. 2008. Análise da atividade turística na reserva particular do patrimônio natural Salto Apepique, Ilhéus, Bahia. Gaia Scientia 2(1):75-82. 
Silva TO, Rocha FA, Oliveira MAP, Oliveira EP. 2007. Avaliação do Ecoturismo em um povoado da Área De Proteção Ambiental da Lagoa Encantada, Ilhéus. Estudos Geográficos, 5(1):15-26.

Sudepe. Superintendência do Desenvolvimento da Pesca. Portaria no 003 de 29 de janeiro de 1982.

Tuan Y. 1980. Topofolia: um estudo da percepção, atitudes e valores do meio ambiente. São Paulo: DIFEL, 289 p.

Van Bellen HM. 2006. Indicadores de Sustentabilidade: Uma Análise Comparativa. 2a ed. Rio de Janeiro: Editora FGV, 226 p.

Veiga JE. 2009. Indicadores Socioambientais: evolução e perspectivas. Revista de Economia Política 29(116): 421-435.

Von Sperling M. 1996. Introdução à qualidade das águas e ao tratamento de esgotos. $2^{\text {a }}$ ed. Belo Horizonte: Departamento de Engenharia Sanitária e Ambiental, Universidade Federal de Minas Gerais, 243 p.

Walter GR. 2002. Economics, ecology-based communities, and sustainability. Ecological Economics 42:81-87. DOI: https://doi.org/10.1016/S0921-8009(02)00048-4.

Yázigi E. 2001. A alma do lugar: Turismo, planejamento e cotidiano. São Paulo: Contexto, 304 p. 